\title{
Ring Chromosome 17 Not Involving the Miller-Dieker Region: A Case with Drug-Resistant Epilepsy
}

\author{
Antonietta Coppola ${ }^{a, c, d}$ Deborah Morrogh ${ }^{b}$ Fiona Farrell ${ }^{a, c}$ \\ Simona Balestrini ${ }^{a, c, e}$ Laura Hernandez-Hernandez ${ }^{a, c}$ S. Krithika ${ }^{a, c}$ \\ Josemir W. Sander ${ }^{a, c, f}$ Jonathan J. Waters ${ }^{b}$ Sanjay M. Sisodiya ${ }^{a, c}$ \\ a Department of Clinical and Experimental Epilepsy, UCL Institute of Neurology, and b North East Thames Regional \\ Genetics Laboratory Service, Hospital for Children NHS Foundation Trust, London, and ${ }^{\mathrm{C} C h a l f o n t}$ Centre for \\ Epilepsy, Chalfont St Peter, UK; ${ }^{d}$ Department of Neuroscience, Reproductive and Odontostomatological Sciences, \\ Epilepsy Centre, Federico II University of Naples, Naples, and ' Neuroscience Department, Marche Polytechnic \\ University, Ancona, Italy; ${ }^{f}$ Stichting Epilepsie Instellingen Nederland (SEIN), Heemstede, The Netherlands
}

\section{Established Facts}

- Ring 17 syndrome is a rare condition with different clinical features depending on whether the MillerDieker critical region (MDCR) is involved.

- Ring 17 syndrome not including MDCR is considered milder, but only 12 cases have been previously described. The genetic and clinical evaluation of this condition might be challenging.

\section{Novel Insights}

- The reported phenotype includes growth delay, intellectual disability, seizures, café-au-lait skin lesions, minor dysmorphism, and a flecked retina. Only 2 previous cases provide description of the epileptic phenotype.

- We report in detail the epilepsy-related features of an individual with ring 17 syndrome not involving MDCR, helping to delineate a possible common phenotype of this condition.

- The present case has also been assessed through exome sequencing to exclude the possibility that known possible genetic factors might have influenced the epileptic phenotype. A comparison with the linear $17 \mathrm{q}$ deletion is also discussed.

\section{Keywords}

Copy number variation · Epilepsy comorbidity ·

Nonconvulsive status epilepticus

\begin{abstract}
Chromosomal abnormalities are often identified in people with neurodevelopmental disorders including intellectual disability, autism, and epilepsy. Ring chromosomes, which usually involve gene copy number loss, are formed by fusion
\end{abstract}

\section{KARGER}

(C) 2017 S. Karger AG, Basel

E-Mail karger@karger.com

www.karger.com/msy
Dr. Antonietta Coppola, MD, PhD

Epilepsy Centre, Department of Neuroscience Federico II University of Naples, Building 17

Via Pansini 5, IT-80131 Naples (Italy)

E-Mail antonietta.coppola1@gmail.com 
of subtelomeric or telomeric chromosomal regions. Some ring chromosomes, including ring 14,17 , and 20 , are strongly associated with seizure disorders. We report an individual with a ring chromosome 17, r(17)(p13.3q25.3), with a terminal 17q25.3 deletion and no short arm copy number loss, and with a phenotype characterized by intellectual disability and drug-resistant epilepsy, including a propensity for nonconvulsive status epilepticus.

(c) 2017 S. Karger AG, Basel

Chromosomal abnormalities identified by newer cytogenetic technologies are emerging as an important genetic association of some epilepsies [Xiang et al., 2010]. In recent years, the increasing number of reports of people with overlapping genetic changes and phenotypes has allowed the delineation of new syndromes (http://decipher. sanger.ac.uk/) [Firth et al., 2009].

Ring chromosomes have been described with all human autosomes. Associated phenotypes vary greatly depending on the chromosomes involved, the size of deleted segments, and the presence or absence of mosaicism [Wyandt, 1988]. Some ring chromosomes, such as ring 20 and ring 14, are associated with a specific seizure phenotype, including status epilepticus. Ring 17 syndrome is a rare condition with different clinical features depending on whether the Miller-Dieker critical region (MDCR), which maps to the short arm of chromosome 17 at 17p13.3, is involved [Shashi et al., 2003]. When this region is deleted (with or without ring 17 chromosome formation), the phenotype includes lissencephaly, severe intellectual disability, and typical facial dysmorphism [Shashi et al., 2003]. Epilepsy has also been reported, but a definite phenotype has not been described [Shimojima et al., 2010]. If MDCR is not involved in ring 17 formation, the phenotype is milder and may include growth delay, intellectual disability, seizures, café-aulait skin lesions, minor dysmorphism, and a flecked retina [Charles et al., 1991; Shashi et al., 2003; Surace et al., 2009].

Only 12 cases of ring chromosome 17 without involvement of MDCR have been described [Qazi et al., 1979; Gass and Taney, 1994; Endo et al., 1999; Shashi et al., 2003; Ricard-Mousnier et al., 2007; Kumari et al., 2009; Surace et al., 2009; de Palma et al., 2015]. Epilepsy has been described in detail in only 2 such cases, with focal seizures from sleep and prolonged nonconvulsive status epilepticus in wakefulness [Ricard-Mousnier et al., 2007; de Palma et al., 2015]. We describe the clinical and EEG features of a further case with ring chromosome 17.

Drug-Resistant Epilepsy in Ring

Chromosome 17

\section{Clinical Report}

This 31-year-old woman is the second child of healthy unrelated parents. There is no family history of epilepsy or any other neurological condition. She was born at term by natural delivery weighing $2.9 \mathrm{~kg}$ (10th percentile). Considering her height, she consistently remained below the 25 th percentile. She initially attained normal developmental milestones, being able to speak 2 languages.

Seizure onset was at age 4 years, when she developed clonic seizures in sleep, followed by different types of seizures in wakefulness, losing her ability to speak. The seizures were well controlled and she spoke again. However, this state was permanently lost with recurring seizures and their increase in frequency.

She has had multiple seizure types including generalized tonicclonic seizures, clonic seizures, tonic seizures from sleep, and complex partial seizures, the latter being the most common type. She has had treatments with many drugs including lamotrigine, phenobarbital, zonisamide, valproate, phenytoin, carbamazepine, vigabatrin, topiramate, levetiracetam, clobazam, clonazepam, gabapentin, and felbamate. She derived some benefit only from lamotrigine and phenobarbital, which reduced the seizure frequency by about $50 \%$. The ketogenic diet was abandoned as she could not tolerate it.

At the age of 10 years, her EEG showed bilateral marked epileptiform abnormalities but with some left-sided predominance. A brain MRI scan at the age of 11 was normal. A subsequent interictal SPECT suggested asymmetry of the temporal lobes with the right lobe showing reduced perfusion in the anterior portion, extending posteriorly.

She was referred at the age of 24 years. She had moderate intellectual disability, could walk with assistance, did not speak, and did not have anal sphincter control. Examination disclosed multiple café-au-lait patches on the back and abdomen as well as multiple white patches on the chest; no obvious dysmorphism was noted. She had daily complex partial seizures, a median of 3 monthly generalized tonic-clonic seizures and 1-2 monthly tonic seizures during sleep. Complex partial seizures were characterized by sudden arrest of activity, staring gaze, hand wringing and lip smacking usually brief lasting 1-2 min but associated with significant postictal tiredness. On referral, her treatment was lamotrigine $375 \mathrm{mg} /$ day, zonisamide $300 \mathrm{mg} /$ day, and phenobarbital $30 \mathrm{mg} /$ day. Phenobarbital and zonisamide were discontinued, and lamotrigine was increased to $550 \mathrm{mg}$ /day. Her social interaction and alertness improved without worsening of seizure frequency.

At age 28, she was admitted due to an increased seizure frequency and cognitive decline. Her EEG showed almost continuous bilateral bursts of spike and wave complexes over a background of theta/ delta activity (Fig. 1). No convulsive seizures had been documented, but she was much less alert, drowsy, and slower than usual (Fig. 1). A diagnosis of nonconvulsive status epilepticus was made and treated with benzodiazepines which led to an improvement.

\section{Methods and Results}

Array-CGH analysis using a NimbleGen $135 \mathrm{~K}$ whole genome v3.0 array chip showed a near-terminal interstitial $0.45-\mathrm{Mb}$ microdeletion within 17q25.3 (chr17:80,572,212,-80,983,971; the genomic region of the corresponding benign $\mathrm{CNV}$ is chr17: 44,353,924-44,766,072; hg19; Fig. 2a). No copy number gain or loss was noted on the chromosome 17 short arm. Examination of
Mol Syndromol 2018;9:38-44

DOI: $10.1159 / 000479949$ 


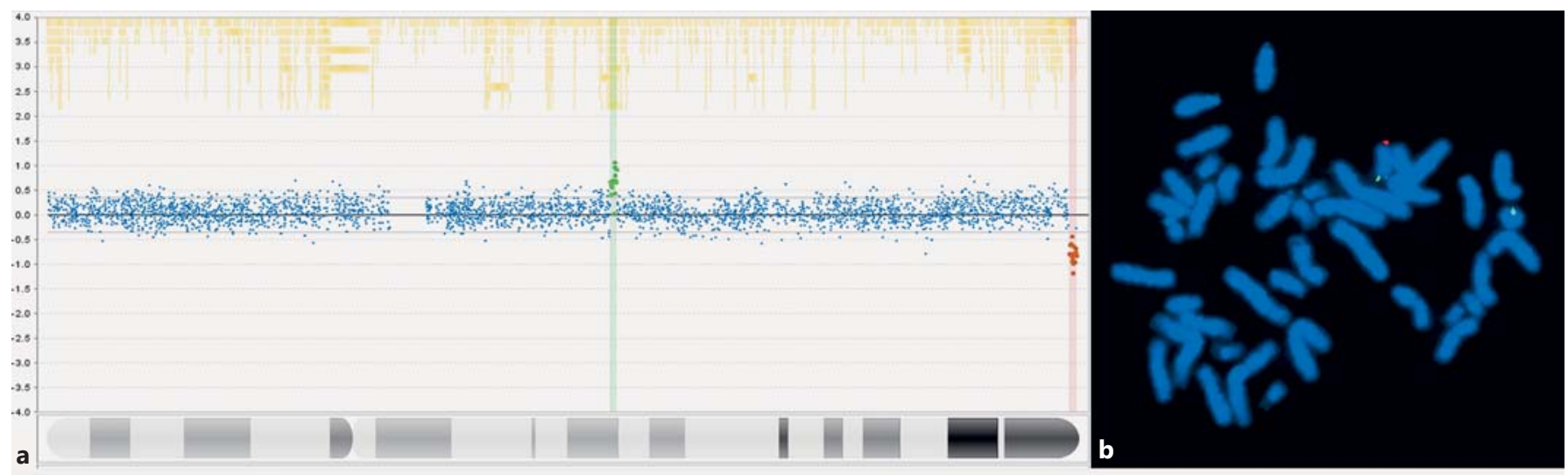

UCSC Genome Browser on Human Feb. 2009 (GRCh37/hg19) Assembly

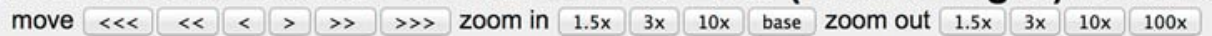

chr17:80,500,000-81,000,000 500,001 bp. enter position, gene symbol or search terms go

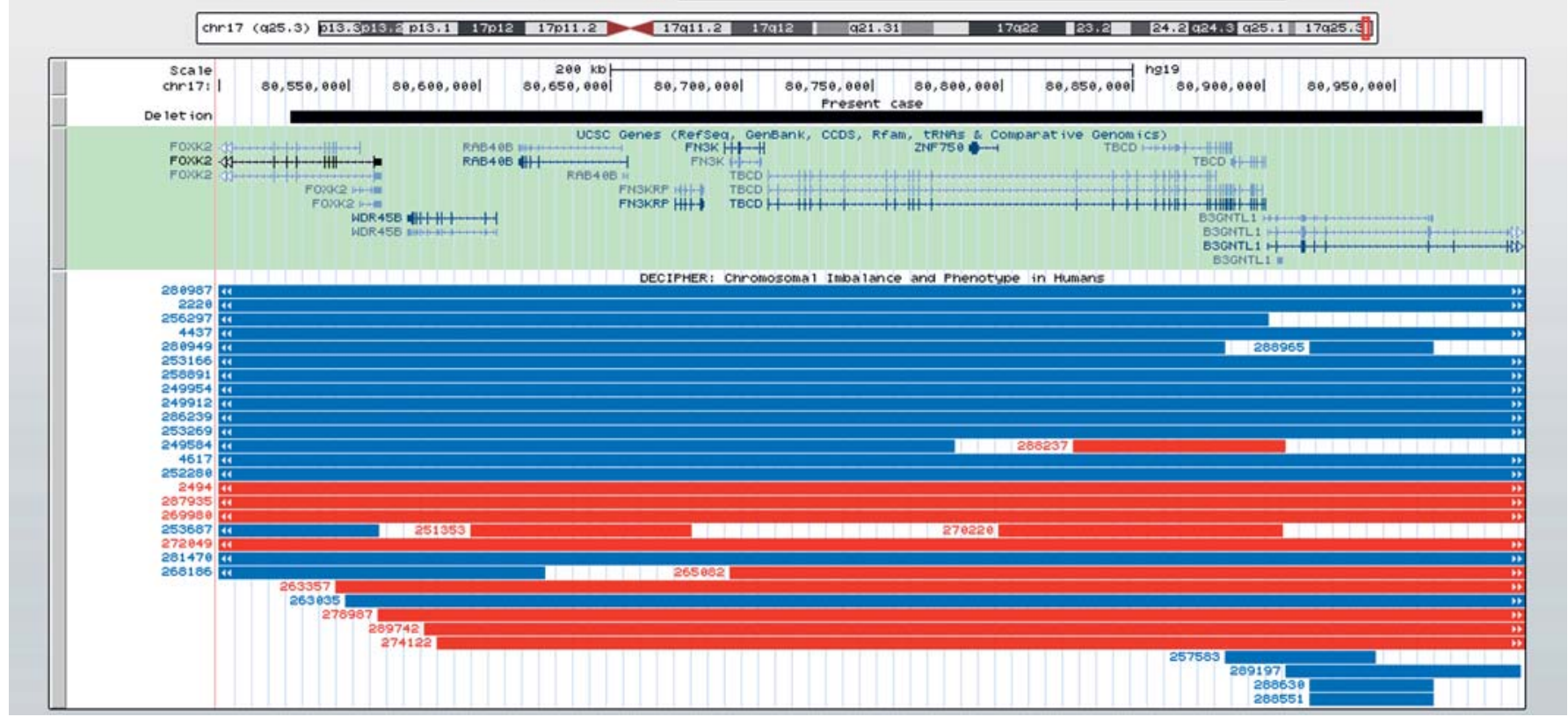

Fig. 1. a Array plot showing 2 CNVs on chromosome 17: a terminal deletion (red spots), which is pathogenic, and a benign duplication (green spots). b FISH preparation showing metaphase chromosomes: Bluegnome BAC probe RP11-567O16 (orange), which maps to 17q25.3, and Cytocell Aquarius subtelomeric probe for $17 \mathrm{p}$ (green). The signals are consistent with the deletion RP11$567 \mathrm{O} 16$ in a ring chromosome identified as ring chromosome 17

30 G-banded metaphases and FISH analysis using Cytocell Aquarius 17pter and RP11-567O16 probes identified a single ring chromosome, r(17)(p13.3q25.3), in all metaphases examined (Fig. 2b). The deletion involved 8 OMIM protein-coding genes (FOXK2, WDR45B, RAB40B, FN3KRP, FN3K, TBCD, ZNF750, B3GNTL1; Fig. 2c). Parental FISH analysis demonstrated that the ring chromosome originated de novo.

We performed whole exome sequencing (mean target coverage of $102.27 ; 82.6 \%$ of bases read at least $30 \times$ ) and interrogated by the presence of a green (17p) signal. The ring chromosome 17 replaces a normal chromosome 17. c UCSC snapshot of chromosome 17 showing the CNV of our case (red box). The black bar indicates a magnification of the CNV, and below, the included genes are reported. Red and blue bars indicate the deletions and duplications, respectively, reported in DECIPHER occurring in the same genomic area. exonic variants occurring in epilepsy-related genes (online suppl. Table 1; see www.karger.com/doi/10.1159/000479949 for all online suppl. material). The exonic library was amplified by Nextera Exome Kit (Illumina), and sequenced on a HiSeq 2500 platform (Illumina). After read alignment, candidate genes were analyzed by VCFtools [Danecek et al., 2011] and annotated using ANNOVAR [Wang et al., 2010]. None of the variants identified were considered pathogenic using the criteria applied (see online suppl. methods for more details). 


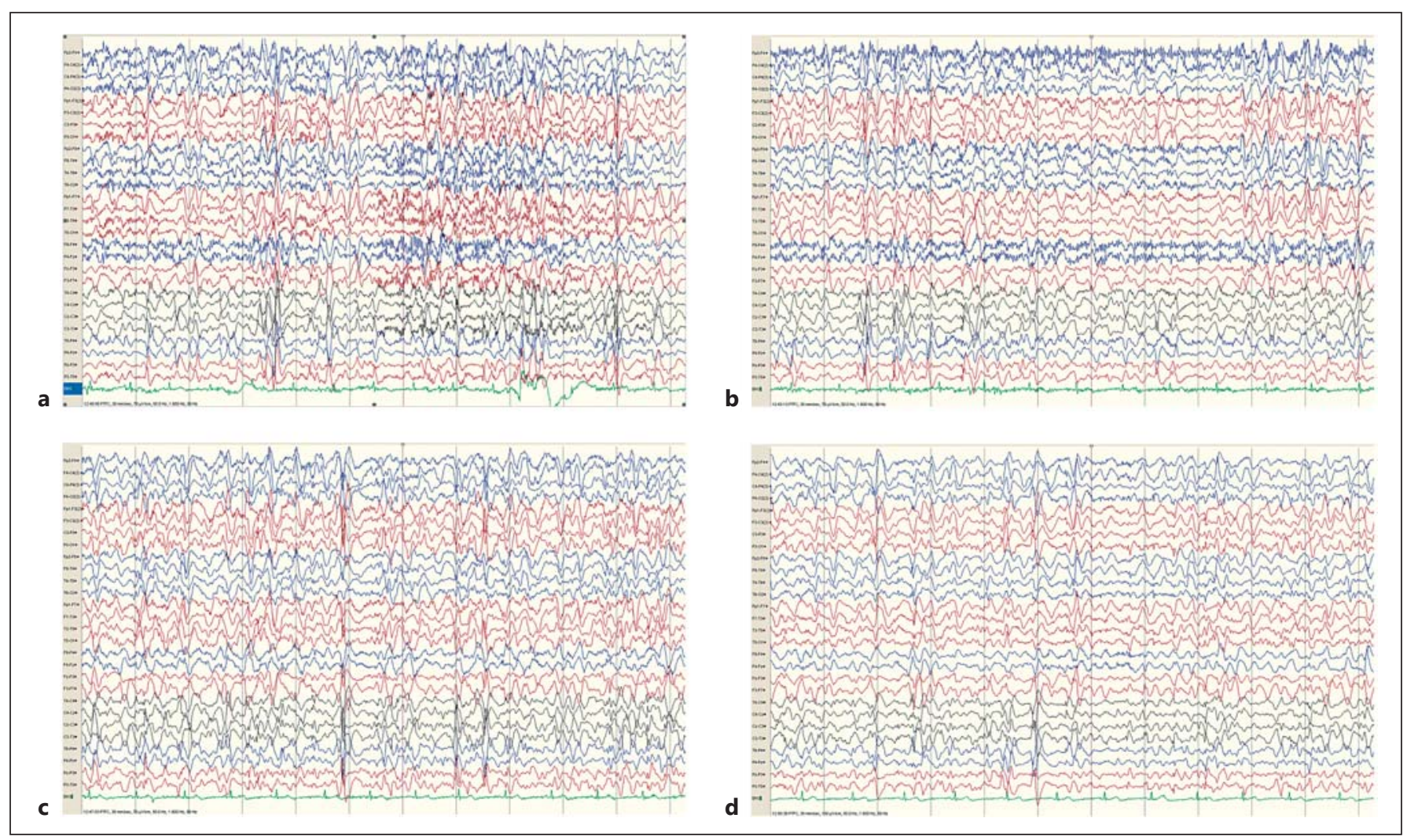

Fig. 2. a-d EEGs recorded at 28 years of age during an episode of nonconvulsive status epilepticus, represented by subcontinuous generalized spike-wave discharges.

\section{Discussion}

Ring chromosome 17 without MDCR involvement is rare [Qazi et al., 1979; Chudley et al., 1982; Charles et al., 1991; Gass and Taney, 1994; Endo et al., 1999; Shashi et al., 2003; Ricard-Mousnier et al., 2007; Kumari et al., 2009; Surace et al., 2009; de Palma et al., 2015]. Epilepsy, although reported in all cases, is well described in only 2 patients, both presenting with nocturnal focal seizures and prolonged diurnal nonconvulsive status epilepticus [Ricard-Mousnier et al., 2007; de Palma et al., 2015]. Isolated linear $17 \mathrm{q}$ deletions are also rare: 13 cases are reported in the DECIPHER database (https://decipher. sanger.ac.uk/search?q=znf750\#consented-patients/results). These present with various dysmorphic features and eye abnormalities other than a flecked retina. Epilepsy is not described in linear $17 \mathrm{q}$ deletion. The clinical features of the cases with ring (17) chromosome and linear $17 \mathrm{q}$ deletion are summarized in Tables 1,2 .

Our case had all the features reported for the other ring (17) cases; although as she had not had an ophthalmo- logical review, we are not certain if she has a flecked retina. The main clinical symptom was drug-resistant epilepsy, which amounted to an epileptic encephalopathy with multiple seizure types, especially featuring nocturnal tonic seizures and nonconvulsive status epilepticus. Her language was most severely affected, with normal acquisition and subsequent loss.

Clinical features of Landau-Kleffner syndrome and Lennox-Gastaut syndrome are present in our case and also in a previously reported case [Ricard-Mousnier et al., 2007], but the electroclinical features are not consistent with either of these conditions. Nonconvulsive status epilepticus was a shared epilepsy phenotype [de Palma et al., 2015]. Detailed data are available from only these 3 cases [our own and Ricard Mousnier et al., 2007; de Palma et al., 2015], but it is possible that polymorphic seizures and nonconvulsive status epilepticus represent the typical presentation of epilepsy in this condition. In our view, a ring (17) abnormality should be considered if a child is affected by drug-resistant epilepsy, featuring nonconvulsive status epilepticus associated with other clinical con- 


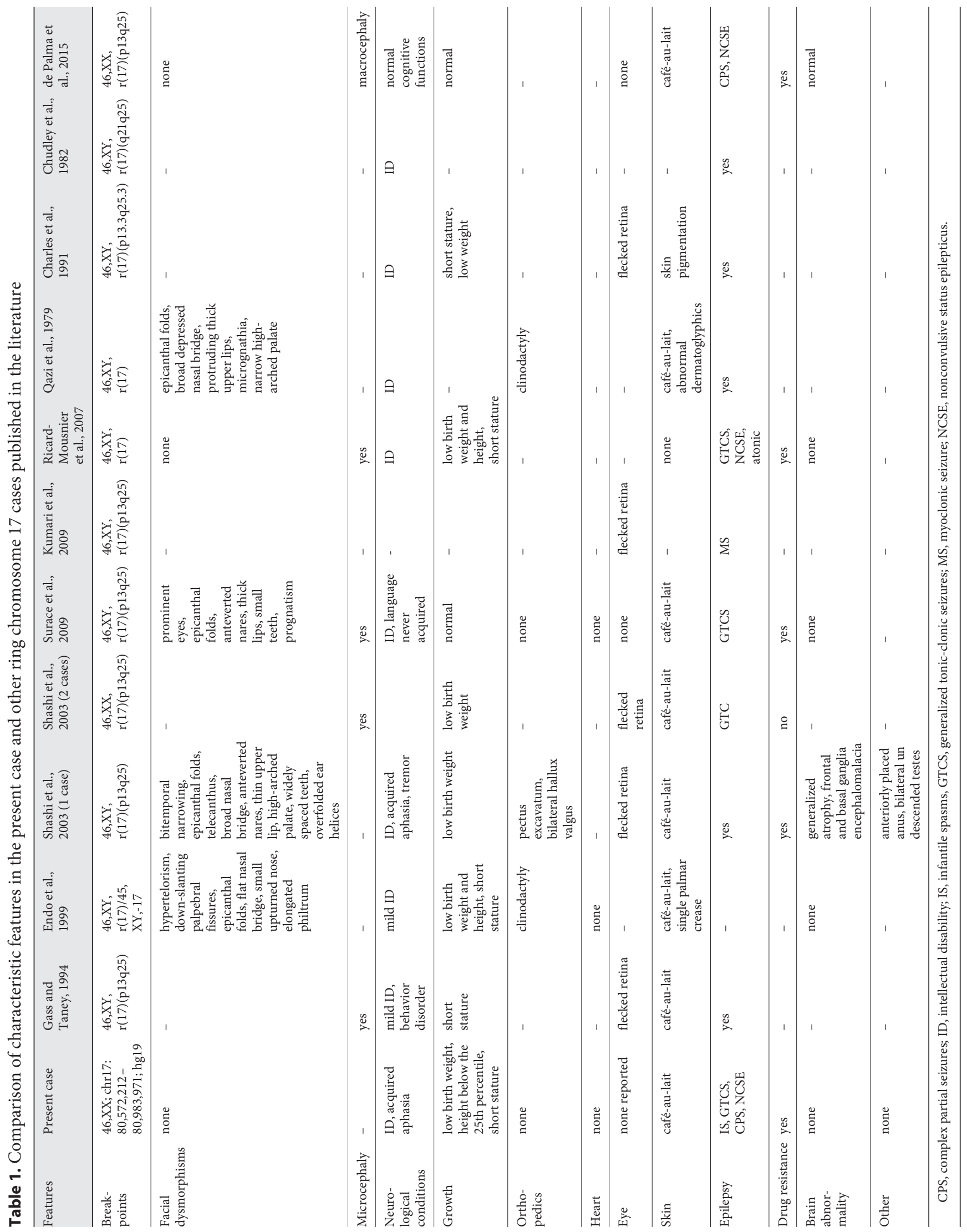


Table 2. Characteristic features of linear $17 \mathrm{q}$ deletions ${ }^{\mathrm{a}}$

\begin{tabular}{|c|c|c|c|c|c|c|}
\hline Breakpoints & $\begin{array}{l}17: 79938892- \\
81048189\end{array}$ & $\begin{array}{l}17: 80544886- \\
81109933\end{array}$ & $\begin{array}{l}17: 80695764- \\
81029941\end{array}$ & $\begin{array}{l}17: 80306702- \\
81108062\end{array}$ & $\begin{array}{l}17: 80561130- \\
81029941\end{array}$ & $\begin{array}{l}17: 79995871- \\
81058252\end{array}$ \\
\hline DECIPHER & 2494 & 263357 & 265082 & 272049 & 278987 & 287935 \\
\hline Facial dysmorphisms & $\begin{array}{l}\text { bifid tongue, midface } \\
\text { retrusion, narrow nasal } \\
\text { bridge, oligodontia, } \\
\text { strabismus, thick nasal } \\
\text { alae, upslanted palpebral } \\
\text { fissures }\end{array}$ & $\begin{array}{l}\text { abnormal facial } \\
\text { shape }\end{array}$ & - & - & - & - \\
\hline Microcephaly & - & - & - & - & - & - \\
\hline Neurological conditions & ID & $\begin{array}{l}\text { global develop- } \\
\text { mental delay }\end{array}$ & $\begin{array}{l}\text { congenital } \\
\text { nystagmus }\end{array}$ & ID & ID, dystonia & ID \\
\hline Growth & - & - & - & - & - & - \\
\hline Orthopedics & $\begin{array}{l}\text { brachydactyly, scoliosis, } \\
\text { tapered fingers }\end{array}$ & - & - & - & - & - \\
\hline Heart & $\begin{array}{l}\text { atrial and ventricular } \\
\text { septum defect }\end{array}$ & - & - & - & - & - \\
\hline Eye & - & - & $\begin{array}{l}\text { cataract, } \\
\text { coloboma, iris } \\
\text { coloboma, } \\
\text { microcornea, } \\
\text { microphthalmos }\end{array}$ & $\begin{array}{l}\text { abnormality } \\
\text { of vision }\end{array}$ & - & - \\
\hline Skin & - & - & - & - & - & - \\
\hline Epilepsy & - & - & - & - & - & - \\
\hline Drug resistance & - & - & - & - & - & - \\
\hline Brain abnormality & - & - & - & - & - & - \\
\hline Other & - & - & $\begin{array}{l}\text { secondary } \\
\text { amenorrhea }\end{array}$ & - & hypothyroidism & \\
\hline
\end{tabular}

ID, intellectual disability. ${ }^{a}$ For DECIPHER Nos. 269980 (80015882-81029941), 274122 (80583427-81029912), 289742 (80578678-81058252), 317239 (80554346-81047565), 304247 (80583427-81044524), 286209 (80583426-81195210), and 287748 (80583426-81195210) no phenotypes are reported.

ditions such as growth delay, intellectual disability, caféau-lait skin lesions, minor dysmorphism, or a flecked retina.

MDCR involvement in ring chromosome 17 helps predict a homogeneous and severe phenotype, but less information is available when this region is not involved. Thus, to date there is no candidate gene for the epilepsy phenotype in the ring chromosome 17 syndrome without MDCR involvement. There are no reports of simple deletions of the long arm of chromosome 17, del(17)(q25.3), to allow comparison.

The chromosomal abnormality in our case is quite small (only $0.45 \mathrm{Mb}$ ) and only includes 8 protein-coding genes, 5 of which are expressed in the brain (FN3KRP, FN3K, TBCD, ZNF750, and BGNTL1). Biallelic mutations affecting $T B C D$ have been found in a rare condition called Sanjad-Sakati syndrome. Epilepsy has been reported in $46 \%$ of these individuals but was never characterized, except in one child with generalized tonic-clonic convulsive status [Elhassanien and Alghaiaty, 2013; Prasad et al., 2013]. The exact functions of the other genes are not known. Whole exome sequencing did not detect variants predicted to be damaging that could possibly explain the phenotype of this individual beyond the ring chromosome.

Ring chromosomes are chromosomal abnormalities which can arise through the fusion of the telomeric regions with or without loss of genetic material [Wyandt, 1988]. Rings are invariably unstable, resulting in cumulative somatic mutations which may be tissue-specific as a result of secondary imbalances involving the ring chromosome. In a recent series of rings, such secondary im- 
balances were observed in $4 / 29$ cases [Guilherme et al., 2013]. We were unable to demonstrate secondary instability in peripheral blood in our case, but this does not preclude the possibility in other tissues. However, the multiple café-au-lait and white patches are indicative of an underlying mosaicism indicating instability of the ring chromosome in this tissue (even if not seen in cultured blood).

A previous review of all ring chromosome 17 cases, without MDCR involvement, showed shared common phenotypic features with no consistency in copy number losses [Charles et al., 1991; Surace et al., 2009]. This observation is supported by our case which, in comparison to the only 2 other cases with a detailed description of epilepsy, showed a discrepant copy number loss [RicardMousnier et al., 2007; de Palma et al., 2015]. It was suggested that alterations in gene expression (other than simply haploinsufficiency) could explain the common phenotypic features found in mild ring 17 syndrome [Surace et al., 2009]. Variation in gene expression within or between tissues could arise either from ring chromosome instability in vivo [Chudley et al., 1982; Wyandt, 1988] and/or as a result of telomere position effects resulting from juxtaposition of actively transcribed sequences in proximity to telomere ends (as a result of ring formation), which may have an impact over long distances [Robin et al., 2014]. Additional cases, with more functional data, may lead to the identification of novel candidate epilepsy genes in ring chromosome 17 syndromes.

\section{Acknowledgments}

We would like to thank the parents for allowing us to report their daughter's case. This work was undertaken at UCLH/UCL. This study was funded in part by the Department of Health's NIHR Biomedical Research Centres funding scheme. The work was also supported by the Freemasons' Grand Charity and Epilepsy Society.

\section{Statement of Ethics}

This research was approved by the institutional ethics committee for the National Hospital for Neurology and Neurosurgery, UCLH, UK, with signed informed parental assent.

\section{Disclosure Statement}

The authors have no conflicts of interest to disclose.

\section{References}

Charles SJ, Moore AT, Davison BC, Dyson HM, Willatt L: Flecked retina associated with ring 17 chromosome. Br J Ophthalmol 75:125-127 (1991).

Chudley AE, Pabello PD, McAlpine PJ, Nickel BE, Shokeir MH: Brief clinical report: ring chromosome 17 in a mentally retarded young man - clinical, cytogenetic, and biochemical investigations. Am J Med Genet 12:219-225 (1982).

Danecek P, Auton A, Abecasis G, Albers CA, Banks $\mathrm{E}$, et al: The variant call format and VCFtools. Bioinformatics 27:2156-2158 (2011).

de Palma L, De Carlo D, Lenzini E, Boniver C, Tarantino V, et al: (2015) Ring 17 syndrome: first clinical report without intellectual disability. Epileptic Disord 17:84-87 (2015)

Elhassanien AF, Alghaiaty HA: Neurological manifestations associated in children with Sanjad-Sakati Syndrome. Int J Gen Med 6: 393-398 (2013).

Endo A, Uesato T, Minato M, Takada M, Takahashi S, Harada K: Ring chromosome 17 syndrome with monosomy 17 mosaicism: case report and literature review. Acta Paediatr 88: 1040-1043 (1999).

Firth HV, Richards SM, Bevan AP, Clayton S, Corpas M, et al: DECIPHER: Database of Chromosomal Imbalance and Phenotype in Humans Using Ensembl Resources. Am J Hum Genet 84:524-533 (2009).
Gass JD, Taney BS: Flecked retina associated with café au lait spots, microcephaly, epilepsy, short stature, and ring 17 chromosome. Arch Ophthalmol 112:738-739 (1994).

Guilherme R, Klein E, Hamid A, Bhatt S, Volleth $M$, et al: Human ring chromosomes - new insights for their clinical significance. Balkan J Med Genet 16:13-20 (2013).

Kumari R, Black G, Dore J, Lloyd IC: Flecked retina associated with ring 17 chromosome. Eye (Lond) 23:2134-2135 (2009).

Prasad R, Kumari C, Mishra OP, Singh UK: Status epilepticus in a child with Sanjad-Sakati Syndrome. BMJ Case Rep 2013:bcr2012007794 (2013).

Qazi OH, Madahar C, Kanchanapoomi R, Giridharan R, Beller E: Ring chromosome 17 in a mentally retarded boy. Ann Genet 22:234238 (1979).

Ricard-Mousnier B, N'Guyen S, Dubas F, Pouplard F, Guichet A: Ring chromosome 17 epilepsy may resemble that of ring chromosome 20 syndrome. Epileptic Disord 9:327-331 (2007).

Robin JD, Ludlow AT, Batten K, Magdinier F, Stadler G, et al: Telomere position effect: regulation of gene expression with progressive telomere shortening over long distances. Genes Dev 28:2464-2476 (2014).
Shashi V, White JR, Pettenati MJ, Root SK, Bell WL: Ring chromosome 17: phenotype variation by deletion size. Clin Genet 64:361-365 (2003).

Shimojima K, Sugiura C, Takahashi H, Ikegami M, Takahashi Y, et al: Genomic copy number variations at 17 p13.3 and epileptogenesis. Epilepsy Res 89:303-309 (2010).

Surace C, Piazzolla S, Sirleto P, Digilio MC, Roberti MC, et al: Mild ring 17 syndrome shares common phenotypic features irrespective of the chromosomal breakpoints location. Clin Genet 76:256-262 (2009).

Wang K, Li M, Hakonarson H: ANNOVAR: functional annotation of genetic variants from high-throughput sequencing data. $\mathrm{Nu}$ cleic Acids Res 38:e164 (2010).

Wyandt H: Ring autosomes: identification, familial transmission, causes of phenotypic effects and in vitro mosaicism, in Daniel A (ed): The Cytogenetics of Mammalian Autosomal Rearrangements (Liss Inc., New York 1988).

Xiang B, Zhu H, Shen Y, Miller DT, Lu K, et al: Genome-wide oligonucleotide array comparative genomic hybridization for etiological diagnosis of mental retardation: a multicenter experience of 1499 clinical cases. J Mol Diagn 12:204-212 (2010).

$44 \quad$ Mol Syndromol 2018;9:38-44

Coppola et al. 